\title{
The Dilemma and Development of Farmers' Professional Cooperative Economic Organization in the Perspective of Rural Social Ecology
}

\author{
Xueqi Xu \\ Wuhan University of Science and Technology \\ Wuhan, China
}

\begin{abstract}
From the perspective of social ecology, this paper examines the two alternative paths that farmer professional cooperatives packaging the rural capital and local farmers' specialized cooperatives in the current farmer professional cooperative economic organizations. This paper points out the dynamic interest balance between the rural capital and the departments and the local cooperative economic organizations. And it also points out the adverse impacts and contradictions to the local social ecology. The contradiction is reflected in the competition of economic interests and resources among the economic organizations. However, the impacts of contradiction on the social ecological balance in rural areas are manifested in politics, economy, culture and other items. The promotion of agricultural industrialization also has political, economic, cultural difficulties and other difficulties. So the development in rural areas should be discussed from the perspective of the overall balanced development of rural social ecology.
\end{abstract}

Keywords-farmers' professional cooperative economic organization; rural social ecology; agricultural industrialization

\section{INTRODUCTION}

In the 30 years since the rural reform, the development of national policies has promoted the agricultural organization from the small-scale peasant economy under the original family contract system to the specialization of peasant households and labors. The key point of developing the rural economy is to organize the peasant economy. In the process of organization, the economic status of the main force is in parallel with the social status, and the social relations in the countryside are also changed. There is a complex interest relationship and cooperation paradox among the capitals, departments and village groups, large farmers and small farmers in various economic organizations. Most of the rural areas obey the local logic of the alienation of the system. The one is the phenomenon of "farmer household eat the smallholders". The big-scale farmers organize the smallscale farmers, and they will save the cost of endogenous transaction and "foreign capital" or "official capital" to carry on the interest negotiation. On the other hand, there is competition between big capital and small capital in resources, industry.

For the development of agricultural industrialization, it considers the farmers' market position and profit space from the perspective of economics. If the policy is implemented only from the concept of interest, then the departments and capital have the profit and various rights in the implementation. The demand for small farmers is multifaceted. And it not only needs to meet the demands of getting income and profitability. Also, the livelihoods of small farmers and cultural ethics decide these things. Small farmers have the needs such as the community welfare, social security, social interaction and other needs of life meaning. Therefore, the organization of farmers should also consider the ways, methods, environment and other aspects of society and other appropriate issues. And then, it can really make this organization has vitality. So that farmers have the ability to autonomously build rural areas, and to make the sustainable development of agriculture.

Before the rural reform, the basic composition of traditional villages which are based on agricultural production is the family. The family is the unit that is based on production, life, association and so on, and is the main body of farming economy. The domestic production space dominated by agriculture is the land. And the rural social contradictions are also concentrated in agricultural activities. Agricultural activities are dominated by the rural farming culture, and they are indispensable parts of the villages. For the farmers in the villages, the cultural lives are also greatly affected in the process of sending the urban capital to the countryside. The circulation of land is directly or indirectly linked to the lifestyles of the farmers. People who would be self-sufficient in agricultural activities will lose the value. In the issue of paying attention to the economic interests of the villagers, the culture of the village as the main body is not completely taken seriously. And the production and living space of the local villagers is deprived, rising to the cultural life of the whole village. And its cultural space is gradually weakened.

\section{ANALYSIS OF RURAL SOCIAL ECOLOGICAL STRUCTURE}

Social ecology is the relationship among the social culture, social relations and social behaviors of human subjects and the ecological environment. It is the interaction between the social system and the ecosystem. There are political, economic and cultural elements in the social system. 
The social ecosystem structure should be analyzed from three dimensions: political ecology, economic ecology and cultural ecology due to its complex multi-layered nature. In the rural social ecology of rural areas, the rural social and political ecology is dominated by rural reform, rural governance policies and the power of all parties in different periods. In the development of agricultural marketization, the rural social economic ecology shows the localism. In the process of modernization, the traditional folk culture, people's culture, faith and other diversified development constitute the rural social and cultural ecology.

\section{A. Social and Political Ecology-the Separation of Power and the Dilemma of Management}

Social and political ecology refers to the whole state that the elements in the political system are formed and displayed in operation and interaction. It is manifested in the configuration of power and the operation of power. The analysis of the social and political ecology in rural areas should be based on the characteristics and development of the power. Political system reform makes the overconcentration of rural power gradually release. The vitality of the development in the rural areas is enhanced. As the collective power weakens, the farmers' political participation is not enough. And then, it returns to the situation that moral constraint is greater than the system constraints. The village collectives only have the ability to advertise the policy, but they don't have the ability to organize. Farmers' autonomy and self-organization would lose the power to drive. Therefore, the self-government reform of the country demands that the villagers also have political autonomy. However, the autonomy of the villagers is driven by the interests, the will and the interpersonal relationships. The villagers don't participate in and distrust the rural selfgovernance. And it forms the dilemma of the rural selfgovernance.

The power is no longer concentrated in the village collectives and the power is gradually divided into many concepts. For the rural society which relies on the geopolitical relationship and blood relationship, the forces of the village that can be connected with the government are village cadres, elite, gangsters, clan power, etc. Basing on these political connections, they have a link and influence in the process of organizing farmers and departments and capital cooperation. They are the key points of the allocation and operation of rural power and the key to resolving the political conflicts between farmers and grass-roots governments.

With the development of the farmers' organizations, it establishes a cooperative economic organization under the guidance of government's autonomy policy and intervention. In the absence of binding, co-ordination and supervision, the role of the township government is transferred from the agent to the speculator. And the public power and public interest are limited and constrained by the grass-roots departments. Therefore, the government's benign policies have changed in the local areas when it is implemented. And then it has sharpened the dilemma of the governance in rural areas.

\section{B. Social and Economic Ecology-Interest Differentiation and Cooperative Dilemma}

The social economic system is composed of economic subject, economic market, economic system and other economic factors. Human is the core of the socio-economic ecology. And it includes the overall state of the interaction between society, economy, education, scientific and technology, ecological environment and other items. Before the socialist transformation, the peasants in the selfsufficiency state were less affected by the market factors. With the expansion of the domestic market, the commercialization of agriculture gradually expanded into the countryside, and the imperfect construction and supply of the rural social system could protect the farmers who trapped in the vulnerable agricultural economy. And they are also involved in the agriculture market. As the main body of the rural agricultural market economy, the interests of farmers need to be protected. And it needs to unify the dispersed interests. The interests of the rural economic structure are transferred from the original unity to the varieties. And the interests of the hierarchical differentiation, industry differentiation, group differentiation, regional differentiation has made some bad influences. The capital makes the speculation on the policy, and the power seeks the resources. Then, the public welfare of interests is transferred to personality. In this way, it makes the distribution of benefits unreasonable. And the conflicts among the subjects of social interests are intensified and the profit margins of farmers are squeezed. Then, it caused the cooperative dilemma.

Economic ecology should be in a win-win cycle. And the relationship should be balanced and sustainable. And it operates the cooperative platform in a benign way. And then, it can form the community of interests. However, in the cooperative relationship, there is an interest sharing between capital and departments. The interests of farmers are dispersed by the distribution system, and the community of farmers is still weak in the interest relationship. The supports of the departments, capital and the collectives for farmers' organizations are established on the relationship of interests. Thus, the economic community has negative externalities. In addition to the unequal market position of the peasants, there are many restrictions on interests. The information is not equal. And the regional differences, industry relationships, government relationships and so on make the interests of farmers unequal within the region, industry, market and the system.

\section{Social and Cultural Ecology_Value Differentiation and Cultural Dilemma}

In the local social environment, the basic characteristics and the overall state of the ideology and the system and organization of the peasantry as the main body constitute the rural social and cultural ecology. The French scholar, Francois Perroux said in the book new concept of development, "economic system always immersed in the cultural environment, and everyone follows the rules of their own groups, customs, and behavior patterns. And it is not completely decided by these things. The culture of rural ideology, from clan to the collectives, is a kind of non- 
individual collectivism culture with regional characteristics and historical inheritance characteristics. And it develops with the continuity of social materialism. To a certain extent, the local cultural endowments are reflected in the local political and economic system. And the political system and economic organizations are also infiltrated in the regional cultural environment. The contradiction during the implementation of the cooperative economic system and the paradox of cooperation is essentially a big problem. And the behavioral relationship and the operation system of stranger society (or the contractual society) are transplanted into the rural acquaintance (or the relationship society). And then, it triggers the problem of the cultural adaptability.

With the acceleration of the modernization, the development of the countryside is facing the deficiency of culture. The traditional values are influenced by the values of the urban society. The religious culture in rural areas breeds the cultural belief of collectivism, which affects the farmers' action strategy and institutional constraints, such as the rules of the civil society, ethics, customs, values, ideology and other informal factors. Coupled with the deficiency of farmers' economic rationality and ecological rationality, they would make an inappropriate choice in the guidance of the top-down policy. When they faced the choice of personal interests, they also need to consider the interests of the neighbors, friends and family. It makes the farmers confined to the dual cultural dilemma of individualism and collectivism. Starting from the autonomy consciousness of the farmers to organize the cooperative economy, the farmers' trade radius is small. And the social interaction and the scope of transactions are relatively narrow. It is limited in the families, tribes and the acquaintance circles. From the spontaneous nature of the farmers, they have no possibilities and no intention to expand or unit with the strangers, outsiders and external forces (such as capital or government). Thus, the transition from the trust of acquaintances to the contractual relationship in the stranger society is the differentiation of the farmers' values. In the values of the interpersonal trust, farmers' cooperation is small and narrow. And cooperatives are single and can't be organized with each other.

It has its own social relationships in rural areas. And the constraints of the system and intervention also make its original closed communication network become more complex. To a certain extent, the blood and geographical relationships is conducive to the cooperation of farmers within certain limits. However, it is still necessary to establish a new trust relationship on the contractual relationship between strangers. And it needs the promotion of cultural consciousness.

\section{CONCLUSION AND SUGGESTION}

In summary, the development of farmers' professional cooperative organizations needs to have the adaptability of social ecology and the sustainability of endogenous forces. To construct the countryside is more like countryside. And it is not deviated from the nature of the countryside. It plays an important role in protecting and recovering the rural values, ecological values, cultural values of the rural society. It has the social significance. It has ecological significance to ensure the balance and stability of the relationship between farmers' material security and production.

If the organization of farmers is only to promote the centralized management of land and the centralized operation, it collectively organizes the farmers to operate land. And then, it can protect the rights of operators. However, it can't fundamentally change the relationships of cooperation paradox between farmers and parties. The centralized management of land is only the integration of resources, or improving the bargaining position of farmers' organizations. However, it couldn't really solve the use of resources, the integration of labors, the optimization of the remaining distribution system and other problems.

At the same time, the national policy has given the local grass-roots units the space of benefit and the departments will seek the profit. It emphasizes the power. And it results into the monopoly. The rules of the rights are included in the individual interests. The public interest is transformed into personal interests, which is inevitable. Agricultural output value driven by the village population should stay in the village. At the same time, it should improve the specific management system to determine the land value-added benefits standard and form. It is not only the overall planning of land. The most important thing is to make the plan of the farmers' professional workforce. And the agricultural operators should be in agriculture and in the local. And then, they will leave the interests in the local, and it would obtain the sustainable development.

\section{REFERENCES}

[1] Lyv Xiaoxia. Analysis of economic and social ecological functions of rural collective economic organizations $[\mathrm{J}]$. Chinese Township Enterprises Accounting, 2008 (9): 4-6.

[2] Fang Jianen, Zhao Xiuli. Analysis on agricultural economic legislation in the perspective of social ecology - Taking the Law of Farmers' Specialized Cooperatives as an Example [J]. Agricultural Archeology, 2011 (6): 195-197.

[3] Feng Hongliang. Social ecology analysis in the transition period of socialism [J]. Academic Exchange, 2009 (4): 134-138.

[4] Luo Guanghua. New Peasant Cooperative Economic Organization and Rural Governance - An Analysis of Framework of Social Capital [J]. Agricultural Economics, 2014 (11): 44-46.

[5] Wang Jianming. Historical evolution, destruction and reconstruction of the rural community in the perspective of ecology [J]. Eco economy (Chinese version), 2013 (9): 34-39. 